\title{
PENGEMBANGAN MANAJEMEN RANTAI PASOK KOPI ARABIKA KINTAMANI BALI
}

\author{
Try Ono Siswandi, A.A.P.Agung Suryawan Wiranatha*, Amna Hartiati \\ PS Teknologi Industri Pertanian, Fakultas Teknologi Pertanian, Universitas Udayana, Kampus Bukit \\ Jimbaran, Badung, Kode pos : 80361; Telp/Fax : (0361) 701801.
}

Diterima 15 Oktober 2018 / Disetujui 18 Februari 2019

\begin{abstract}
The purpose of this study were to determine the condition of Kintamani Arabica coffee supply chain management which included the structures, mechanisms and institutional supply chain, and to determine the priority of the recomendations of the development in order to improve the performance management of the supply chain of Arabica Coffee Kintamani. The research was carried out at the Catur Village in Kintamani Subdistrict, Bangli Regency, up to the distribution channel to Denpasar. The instrument used to collect supply chain performance data were questionnaires. The format of the questionnaire followed to the terms and conditions required by AHP. The distribution pattern of Kintamani Arabica coffee is: Pattern 1: Farmers $\rightarrow$ UPH $\rightarrow$ Coffee shop $\rightarrow$ End consumers. Pattern 2: Farmers $\rightarrow$ Cooperation $\rightarrow$ End consumers. Pattern 3: Farmers $\rightarrow$ Collectors $\rightarrow$ PT. Mengani $\rightarrow$ Retailers $\rightarrow$ End consumers. The results of the analysis with the AHP method indicated that the criteria of increasing access to market, alternative management costs, and production cost performance indicators were the priority that plays a role in the development of a competitive supply chain management system for Kintamani Arabica coffee.
\end{abstract}

Keywords : AHP Method, Supply Chain, Arabica Coffee

\begin{abstract}
ABSTRAK
Tujuan dari penelitian ini adalah mengetahui kondisi manajemen rantai pasok kopi Arabika Kintamani yang meliputi struktur, mekanisme, dan kelembagaan rantai pasok dan mengetahui prioritas rekomendasi pengembangan dalam rangka meningkatan kinerja manajemen rantai pasok kopi arabika Kintamani. Penelitian dilaksanakan di tingkat petani Desa Catur Kecamatan Kintamani, Kabupaten Bangli, sampai jalur distribusi hingga Denpasar penelitian untuk mengetahui jalur ditribusi kopi arabika kintamani. Instrument yang digunakan untuk mengumpulkan data kinerja rantai pasok yaitu menggunakan kuesioner. Format kuesioner mengikuti persyaratan dan ketentuan yang diperlukan sesuai dengan metode AHP. Pola rantai pasok kopi arabika Kintamani adalah sebagai berikut: Petani $\rightarrow$ UPH $\rightarrow$ Kopi shop $\rightarrow$ Konsumen akhir. Pola II: Petani $\rightarrow$ Koperasi $\rightarrow$ Konsumen akhir. Pola III: Petani $\rightarrow$ Pengepul $\rightarrow$ PT. Mengani $\rightarrow$ Grosir/retiler $\rightarrow$ Konsumen akhir. Hasil analisis dengan metode AHP menunjukkan bahwa kriteria meningkatkan nilai tambah, alternatif reliabilitas, dan indikator kinerja kualitas proses menjadi prioritas yang berperan dalam rangka pengembangan sistem manajemen rantai pasokan kopi arabika Kintamani yang berdaya saing.
\end{abstract}

Kata kunci : Metode AHP, Rantai Pasok, Kopi Arabika

*Korespondensi Penulis:

Email : agung_suryawan@unud.ac.id 


\section{PENDAHULUAN}

Kopi merupakan komoditas utama yang diperdagangkan di seluruh dunia dengan kontribusi setengah dari total ekspor komuditas tropis. Popularitas dan daya tarik dunia terhadap kopi, utamanya dikarenakan rasanya yang unik serta didukung oleh faktor sejarah, tradisional, sosial dan kepentingan ekonomi (Ayelign et al., 2013). Kopi yang dijual dipasar dunia biasanya kombinasi dari biji kopi varietas arabika dan robusta. Perbedaan antara kedua kopi ini adalah kadar kafeinnya. Wilayah subtropis dan tropis merupakan lokasi yang baik untuk budidaya kopi. Oleh karena itu, negara-negara yang mendominasi produksi kopi dunia berada di wilayah Amerika Selatan, Afrika dan Asia Tenggara. Minuman kopi dengan bahan dasar ekstraksi biji kopi dikonsumsi sekitar 2,25 milyar gelas setiap hari didunia (Ponte, 2002).

Rantai pasok sebagai kesatuan dapat mengambil langkah yang tepat untuk mengatasi atau menekan dampak buruk risiko secara bersamaan (Syarif.et al 2012). Unsurunsur ketidakpastian para pelaku atau aktor rantai pasok yang beragam dapat dipadukan secara harmonis. Model Analytical Hierarchy Process (AHP) dapat digunakan untuk merancang skenario perbaikan kinerja rantai pasok dalam hal peningkatan produktivitas (Marimin, et al. 2014).

Konsep metode AHP pertama kali diperkenalkan oleh DR. Thomas L. Saaty dari Wharton School of Business pada tahun 1971-1975, yang merupakan suatu konsep untuk merubah nilai-nilai kualitatif menjadi nilai kuantitatif sehingga keputusankeputusan yang diambil bisa lebih obyektif. Metode AHP mula-mula dikembangkan di Amerika pada tahun 1970 dalam hal perencanaan kekuatan militer untuk menghadapi berbagai kemungkinan (contingency planning). Kemudian dikembangkan di Afrika khususnya di Sudan dalam hal perencanaan transportasi. (Supriyono,et al.,2007).

Tujuan dari penelitian ini adalah untuk mengetahui kondisi manajemen rantai pasok kopi Arabika Kintamani yang meliputi struktur, mekanisme, dan kelembagaan rantai pasok, dan mengetahui prioritas rekomendasi pengembangan dalam rangka meningkatan kinerja manajemen rantai pasok kopi arabika Kintamani.

\section{METODE PENELITIAN}

Penelitian dilaksanakan di tingkat petani Desa Catur Kecamatan Kintamani, Kabupaten Bangli, sampai jalur distribusi hingga Denpasar.

\section{Instrumen dan Metode Pengumpulan Data}

Instrument untuk mengumpulkan data kinerja rantai pasok yaitu menggunakan kuesioner. Format kuesioner mengikuti persyaratan dan ketentuan yang diperlukan sesuai dengan metode AHP. Metode pengumpulan data adalah dengan menggunakan wawancara secara langsung dan survei menggunakan kuisioner.

\section{Responden Penelitian}

Responden dalam penelitian ini meliputi dua kategori yaitu: (1) Responden untuk pengumpulan data tentang struktur, mekanisme, kelembagaan rantai pasok kopi arabika, dan (2) Responden untuk pengukuran kinerja rantai pasok kopi arabika. Responden untuk pengumpulan data merupakan individu-individu yang berasal dari pemangku kepentingan. Adapun pemangku kepentingan (stakeholder) yang diikutkan dalam pengumpulan data ini antara lain petani, pengepul, pedagang dan pengecer. Pengambilan sampel petani dilakukan secara purposive sampling. Purposive sampling merupakan teknik pengambilan sampel secara acak dengan 
memperhatikan pertimbangan-pertimbangan yang dibuat oleh peneliti. Dalam hal ini yang dijadikan pertimbangan adalah para petani yang melakukan usaha tani secara sungguhsungguh, yaitu:

1. Melakukan budidaya kopi arabika secara continue dalam waktu yang lama.

2. Menghasilkan kopi arabika dengan kuantitas yang relatif stabil pada setiap musim panen.

Sedangkan pemilihan responden pada middleman dan supermarket/pasar tradisional digunakan metode bola salju (snowball sampling).

Pengukuran kinerja rantai pasok menggunakan para pakar dibidang budidaya, pemasaran dan proses produksi (profesional dibidang kopi arabika) sebanyak 5 orang pakar. Pakar responden yang dipilih, didasarkan atas pertimbangan dan kreteria (Marimin, 2001):

1. Pengakuan secara obyektif terhadap kemampuan profesional yang dimiliki oleh lingkungan akademik dan masyarakat luas.

2. Produktifitas yang tinggi didalam bidang ilmiah yang diketahui.

3. Mempunyai reputasi, kedudukan dan telah menunjukkan kredibilitas sebagai ahli.

4. Telah berpengalaman dibidangnya minimal 5 tahun.

5. Pakar yang berpendidikan formal S2/S3 pada pengembangan pertanian atau agroindustri.

6. Pakar yang berasal dari praktisi didalam kehidupan sehari-hari (kaya akan pengalaman empiris disuatu sektor kegiatan ekonomi) dalam bidang pertanian atau agroindustri. Klasifikasi pakar ini lebih didasarkan pada lama kerja dan wewenang (dapat terdidik secara formal atau otodidak) disuatu posisi kegiatan teknik tertentu.
Para pakar yang memberikan pembobotan terhadap kuisioner AHP adalah :

1. Prof. Dr. Ir. I Ketut Satriawan, M.T selaku dosen pada Fakultas Teknologi Pertanian Universitas Udayana dan dosen ahli kopi dan manajemen.

2. Prof. Ir. I.G.A.A Ambarawati, M.Ec,Ph.D selaku guru besar sosial ekonomi pertanian pada Fakultas Pertanian Universitas Udayana dan dosen ahli dalam manajemen rantai pasok dan bisnis internasional.

3. I Wayan Gede Sedana Yoga, S.TP.,M.Agb selaku dosen pada Fakultas Teknologi Pertanian Universitas Udaya dan dosen ahli kopi dan manajemen rantai pasok.

4. I Ketut Jati selaku petani kopi arabika, ketua MPIG (Masyarakat Perlindungan Indikasi Geografis) dan ketua UPH Triguna Karya.

5. I Ketut Samia sebagai sekretaris Koperasi MPIG kopi arabika Kintamani Bali.

\section{HASIL DAN PEMBAHASAN}

\section{Struktur rantai pasok}

Rantai pasok adalah suatu konsep penerapan sistem logistik yang terintegrasi dalam aktivitas bisnis, yang merupakan mata rantai penyediaan barang dari bahan baku sampai barang jadi. Ada tiga macam aliran yang harus dikelola didalam rantai pasok. Pertama adalah aliran produk dari hulu (upstream) ke hilir (downstream), kedua adalah aliran uang yang mengalir dari hilir ke hulu, dan yang ketiga adalah aliran informasi yang mengalir dari hulu ke hilir dan dari hilir ke hulu. Gambar 1 menunjukkan struktur rantai pasok kopi arabika Kintamani 


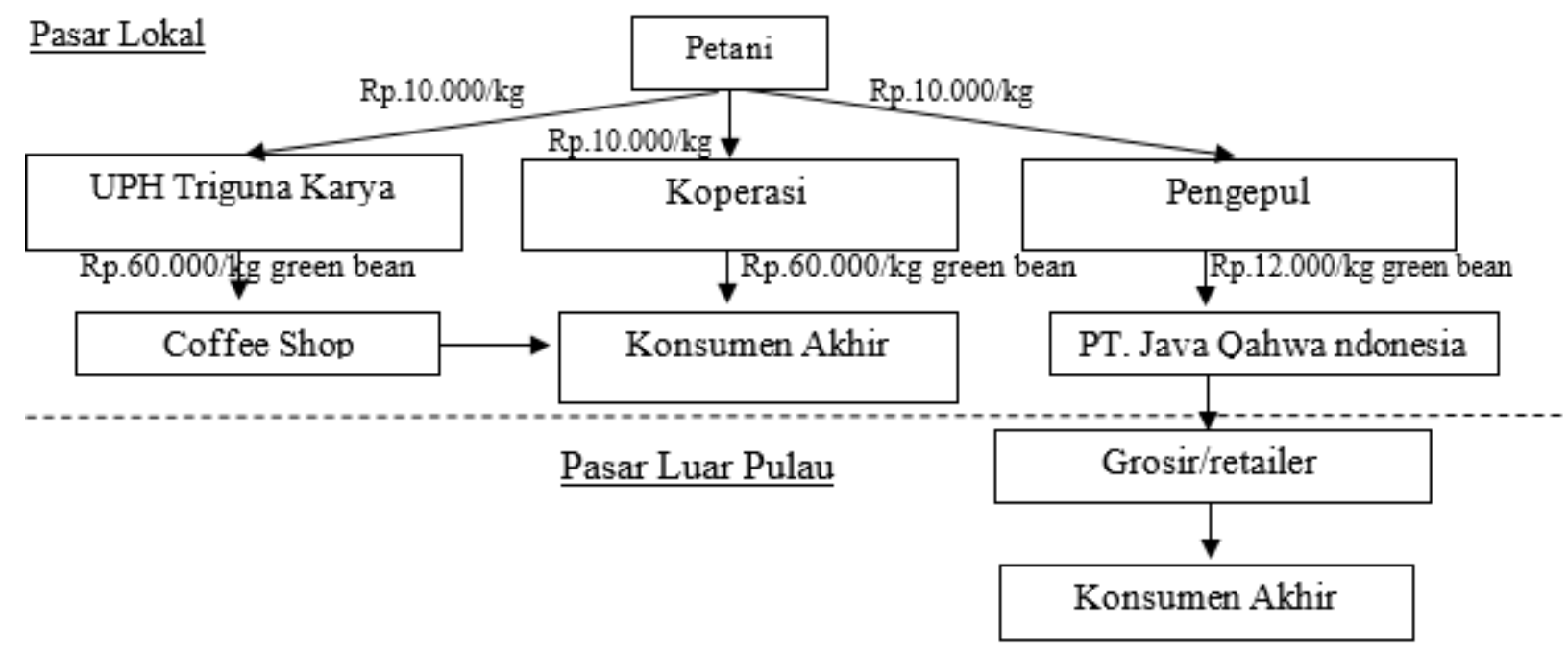

Gambar 1. Pola aliran dalam rantai pasok kopi arabika Kintamani

Dari Gambar 1. diperoleh tiga pola aliran, yaitu:

a. Pola I: $\quad$ Petani $\rightarrow$ UPH $\rightarrow$ Coffee Shop $\rightarrow$ Konsumen akhir

b. Pola II: Petani $\rightarrow$ Koperasi $\rightarrow$ Konsumen akhir.

c. Pola III: Petani $\rightarrow$ Pengepul $\rightarrow$ PT. Mengani $\rightarrow$ Grosir/retiler $\rightarrow$ Konsumen akhir.

Rantai pasok kopi arabika dimulai dari petani. Kopi arabika dikumpulkan oleh perantara (middleman) UPH, koperasi dan pengepul dari petani. UPH dan Koperasi menghantarkan kopi arabika kepada custumer yaitu coffee shop, hotel maupun villa yang memiliki hubungan kemitraan dengan UPH dan koperasi. Sesampainya di coffe shop, hotel maupun villa kemudian kopi arabika dijual eceran kepada konsumen akhir yang merupakan pengunjung dari coffe shop, hotel dan villa tersebut. Kopi arabika yang disalurkan melalui pengepul dijual kepada PT Java Qahwa Indonesia dan akan diproses untuk didistribusikan ke konsumen.

Aliran uang mengalir dari hilir ke hulu (Sucipta, 2017). Uang akan mengalir dari konsumen coffee shop, hotel maupun villa, UPH, koperasi dan petani. Pasar PT Java Qahwa Indonesia meliputi supermarket dan toko oleh-oleh yang ada di Denpasar dan menyuplai untuk kebutuhan kopi luar negeri sehingga jalaur aliran uang lebih panjang. Dalam penelitian penulis kali ini hanya menekankan aliran rantai pasok dari petani kopi Kintamani hingga pasar mencapai Denpasar. Sistem pembayaran ditingkat petani biasanya secara langsung sesuai dengan jumlah kopi yang diambil. Ditingkat pengepul dan UPH, pembayaran tidak dilakukan secara langsung, sistem pembayaran sesuai perjanjian dan biasanya paling lambat dua minggu.

Aliran informasi dan komunikasi sudah terintegrasi antara anggota rantai pasok. Informasi mengalir dari konsumen akhir hingga ke petani dan sebaliknya. Informasi tersebut biasanya seperti informasi mengenai harga, jumlah, dan kualitas.

Pola I menunjukkan aliran rantai pasok kopi arabika mulai dari petani sebagai produsen kopi arabika. Kopi arabika yang siap panen dijual ke UPH sebagai rantai kedua dalam pola I. Kopi arabika yang sudah siap panen kemudian dipetik secara manual menggunakan tenaga manusia. Harga untuk 1 kilogram kkopi arabka gelondong merah yaitu Rp. 10.000. selanjutnya hasil panen dibawa ke UPH untuk diolah menjadi green beans. Proses produksi yang dilakukan di UPH yaitu proses olah basah. Setelah proses 
produsi selesai, pihak UPH menjual kopi green beans ke coffee shop yang sudah melakukan pemesanan secara rutin maupun tidak rutin. Harga perkilogram kopi green beans yaitu Rp. 60.000. Rantai pasok ketiga dalam pola I yaitu coffee shop. Coffee shop menjual hasil olahan kopi green beans kepada pengunjung dari coffe shop. Harga yang ditawarkan untuk satu cangkir kopi seduhan arabika bervasiasi, dimulai dengan harga $\mathrm{Rp}$. 20.000 sampai dengan Rp. 40.000 per cangkir kopi arabika.

Pola II dalam rantai pasok kopi arabika Kintamani yaitu dimulai dari petani sebagai penghasil kopi arabika. Kopi arabika yang sia dipanen adalah kopi yang sudah mulai berwarna merah. Kopi yang dibeli oeh ihak koperasi yaitu kopi gelondong merah yang diproses untuk dijadikan kopi green beans. Harga kopi gelondog merah yang dibeli oleh pihak koperasi yaitu Rp. 10.000 perkilogramnya. Seteah roses produksi selesai selanjutnya pihak koperasi memasarkan hasil produksi nya ke konsumen akhir. Harga yang diberikan pihak koperasi untuk dipasarkan ke konsumen akhir yaitu Rp. 60.000 perkilogram untuk hasil olah green beans.

Pola III rantai pasok kopi arabika Kintamani yaitu dimulai dari petani yang menjual hasil panennya kepada pengepul dengan harga Rp. 10.000 perkilogram kopi arabika gelondong merah. Setelah proses panen selesai, pengepul menjual hasil panen kopi arabika kepada PT Java Qahwa Indonesia dengan harga Rp. 12.000 perkilogram untuk hasil panen kopi arabika gelondong merah. PT Java Qahwa Indonesia melakukan proses pengolahan kopi untuk dipasarkan keluar pulau Bali.

\section{Mekanisme rantai pasok}

Mekanisme rantai pasok produk pertanian dapat bersifat tradisional ataupun modern. Mekanisme produk pertanian yang bersifat tradisional yaitu petani menjual produk langsung ke pasar atau melalui perantara. Mekanisme rantai pasok yang bersifat modern terbentuk oleh beberapa hal, antara lain dalam rangka mengatasi kelemahan karakteristik dari produk pertanian, meningkatkan kesejahteraan petani dasi sisi ekonomi dan sosial (Marimin, dkk., 2013).

Mekanisme rantai pasok kopi arabika Kintamani bersifat modern karena sudah adanya kelembagaan yang dibentuk oleh pemerintah dan mendapatkan respon positif dari petani. Tujuan dari terbentuknya kelembaagn ini adalah menanggulangi kelemahan dari hasil produksi kopi dan meningkatkan kesejahteraan ekonomi petani. Kelembagaan yang bentuk pemerintah dan mendapatkan respon positif tersebut antara lain, subak abian, UPH dan koperasi tani.

\section{Kelembagaan rantai pasok}

Kelembagaan rantai pasok merupakan hubungan manajemen atau sistem kerja yang sistematis dan saling mendukung diantara beberapa lembaga kemitraan rantai pasok dalam suatu komoditas. Tujuan kelembagaan rantai pasok adalah menanggulangi kelemahan dari hasil panen dan meningkatkan sosial kesejahteraan ekonimi petani.

Bentuk kelembagaan rantai pasok pertanian terdiri dari dua pola yaitu pola perdagangan umum dan pola kemitraan. Pola perdagangan umum melibatkan berbagai pelaku tata niaga yang umum ditemukan di banyak lokasi, antara lain petani baik secara individu mapun kelompok dan pedagang baik berada di sentra produksi maupun pedagang besar yang berada di pusat kota. Ikatan petani dan pedagang merupakan ikatan langganan baik tanpa adanya kontrak perjanjian. Sedangkan untuk pola kelembagaan kemitraan merupakan hubungan kerja diantara beberapa pelaku rantai pasok yang menggunakan mekanisme perjanjian atau kontrak tertulis dalam jangka waktu tertentu 
(Marimin, dkk., 2013).

\section{Analisis Pengembangan Sistem Manajemen Rantai Pasok Kopi Arabika}

Upaya pengembangan manajemen rantai pasok kopi arabika bertujuan meningkatkan kinerja rantai. Menurut Van der Vorst (2006), kinerja rantai pasok merupakan tingkat kemampuan rantai pasok mengoptimalkan jaringan rantai dan meningkatkan daya saing pelaku rantai pasok.

\section{Penyusunan Hierarki}

Setiap pendapat pakar dievaluasi dengan menggunakan tolok ukur konsistensi yang menggunakan Consistensi Ratio (CR). Tolok ukur CR ini menggambarkan tingkat konsistensi pendapat pakar terhadap kreteriakreteria keputusan yang dianalisis melalui perbandingan berpasangan. Tolok ukur yang digunakan dalam analisis ini adalah lebih kecil atau sama dengan 0,1 merupakan nilai baik dan dapat dipertanggung jawabkan. Bila CR yang diperoleh dari pakar lebih besar dari 0,1 maka pendapat pakar tersebut tidak digunakan sebagai analisis. Pendapat pakar yang memiliki CR memenuhi syarat digabungkan dan diolah menggunakan ratarata geometrik (geometric mean) sehingga diperoleh hasil berupa pendapat gabungan (agresi pakar)

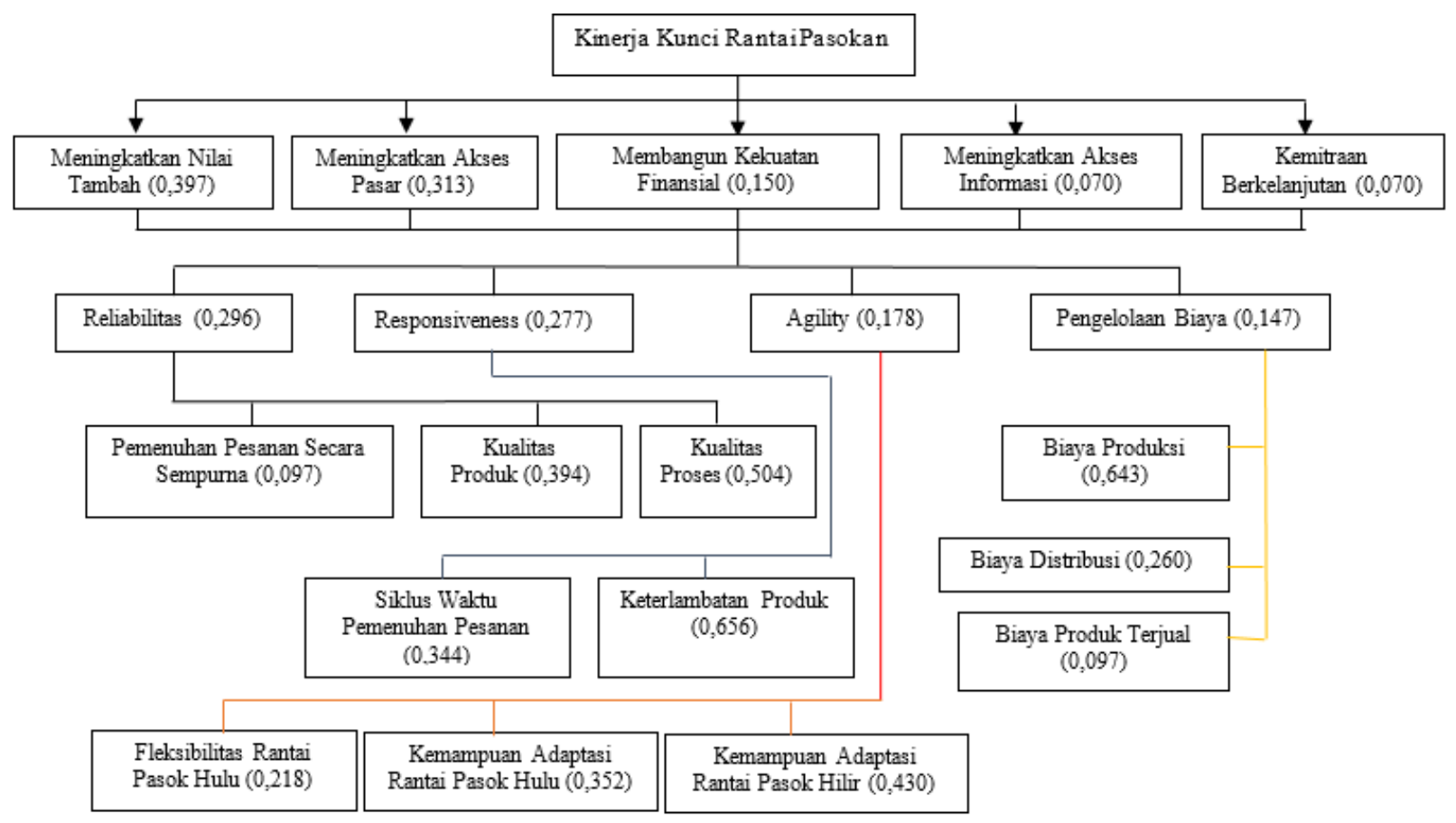

Gambar 2. Penyusunan struktur hierarki keputusan

\section{Penentuan prioritas indikator kinerja kunci}

Penentuan indikator kinerja kunci dalam penelitian ini ditentukan dengan analisis perbandingan berpasangan menggunakan metode analytical hierarchy process Indikator kinerja merupakan kriteria yang dapat digunakan untuk mengukur kinerja produk, jasa dan proses produksi.
Dalam mengembangkan kinerja rantai pasok, maka perlu dipertimbangkan bahwa masingmasing anggota rantai pasok memiliki tujuan, kriteria, dan indikator kinerja yang berbeda. Pengembangan tersebut tidak selalu berdampak positif terhadap kinerja rantai pasok secara keseluruhan karena perbaikan kinerja pada setiap anggota rantai pasok memungkinkan terjadinya kerugian anggota 
lainnya. Dengan demikian, indikator kinerja rantai pasok harus diidentifikasi untuk menetapkan dimensi kritis yang memberikan rekomendasi bagi keberhasilan rantai secara keseluruhan.

Menurut Alim S. dkk. (2010), pengukuran kinerja suatu rantai pasok merupakan permasalahan pengambilan keputusan kriteria majemuk dengan berbagai alternatif kuantitatif dan kualitatif. Untuk itu, dipilih metode analytical hierarchy process (AHP) yang dikembangkan oleh Saaty, karena metode tersebut sudah secara luas digunakan untuk memilih alternatif yang jauh lebih baik diantaranya. Dengan menggunakan AHP, suatu persoalan yang akan dipecahkan dalam suatu kerangka berpikir terorganisasi, sehingga memungkinkan dapat diekspresikan untuk mengambil keputusan yang efektif dari sebuah permasalahan. Pendekatan AHP juga ditujukan untuk menyusun ketidakpastian dan keraguan yang dihubungkan dengan penilaian dari penentuan bobot masingmasing metrik pengukuran kinerja, sehingga memberikan suatu uraian yang lebih akurat tentang proses pengambilan keputusan.

Dalam AHP, perbandingan berpasangan (pairwaise comparisen) pada masing-masing tingkat dengan orientasi pada tujuan pemilihan alternatif terbaik dilakukan dengan menggunakan suatu skala sembilan poin. Skala tersebut menunjukkan penilaian pakar, yaitu sama penting, sedikit lebih penting, lebih penting, sangat lebih penting, dan mutlak lebih penting.

Hirarki indikator kinerja kunci merujuk pada suatu penelitian terkait dengan Pengembangan Rantai Pasok Buah Manggis di Kabupaten Bogor, Jawa Barat. Indikator kinerja kunci diidentifikasi melalui 3 sudut pandang, yaitu tujuan rantai pasok, atribut kinerja, dan indikator kinerja (Astuti, 2012).

Berdasarkan pendapat para pemangku kepentingan, kriteria utama rantai pasok kopi arabika Kintamani adalah meningkatkan nilai tambah dengan bobot kepentingan sebesar 0,397. Alternatif untuk mencapai tujuan utama tersebut adalah alternative reliabilitas dengan bobot kepentingan sebesar 0,296, dengan indikator kinerja kunci adalah kualitas proses dengan nilai sebesar 0,054, kualitas produk dengan bobot kepentingan sebesar 0,394 dan pemenuhan secara sempurna dengan nilai bobot kepentingan sebesar 0,097.

\section{KESIMPULAN}

\section{Kesimpulan}

Berdasarkan penelitian yang telah dilakukan maka dapat disimpulkan beberapa hal sebagai berikut:

1. Pola rantai pasok kopi arabika Kintamani adalah sebagai berikut: Pola I: Petani $\rightarrow$ UPH $\rightarrow$ Coffee

shop $\rightarrow$ Konsumen akhir. Pola II: Petani $\rightarrow$ Koperasi $\rightarrow$ Konsumen akhir. Pola III: Petani $\rightarrow$ Pengepul $\rightarrow$ PT Java Qahwa Indonesia $\rightarrow$ Grosir/retailer $\rightarrow$ Konsumen akhir. Mekanisme rantai pasokan kopi arabika Kintamani masih bersifat tradisional. Petani sebagai produsen belum membentuk kemitraan berdasarkan kontrak dengan pelaku rantai pasok lainnya. Sehingga kesejahteraan petani belum sepenuhnya terjamin, karena belum mendapatkan kepastian pembelian hasil panennya. Kelembagaan rantai pasokan kopi arabika Kintamani termasuk pola perdagangan umum. Sistem jual beli produk belum menerapkan kontrak perjanjian yang mengikat antar pelaku terutama petani dengan middleman sehingga hanya mengandalkan kepercayaan.

2. Hasil analisis dengan metode AHP menunjukkan bahwa kriteria meningkatkan nilai tambah, alternatif reliabilitas, dan indikator kinerja kualitas proses menjadi prioritas yang berperan 
dalam rangka pengembangan sistem manajemen rantai pasokan kopi arabika Kintamani.

\section{Saran}

Berdasarkan hasil penelitian ini dapat disarankan beberapa hal sebagai berikut :

1. Rekomendasi diusulkan guna meningkatkan kinerja sistem manajemen rantai pasokan kopi arabika Kintamani agar mampu berdaya saing, perlu dukungan dari seluruh pelaku rantai pasok secara sungguh-sungguh agar dapat terlaksana secara optimal. Hal ini dapat diwujudkan melalui perencanaan kolaboratif yang merupakan kesatuan kerjasama dan penyelarasan informasi antara satu anggota rantai dengan anggota lainnya dalam perencanaan produksi maupun perencanaan penjualan

2. Pendampingan yang dilakukan oleh pihak pemerintah perlu ditingkatkan dan perlu adanya pendampingan dari pihak perguruan tinggi terkait dengan budidaya sampai penanganan pasca panen. Dengan adanya program pendampingan, maka standar operasional prosedur (SOP), Good Agriculture Pratices (GAP) dapat terlaksana. Sehingga diharapkan terbentuknya rantai nilai yang berkelanjutan, dan menciptakan kesejahteraan di antara pelaku usaha di sepanjang rantai pasok.

3. Untuk penelitian selanjutnya, perlu dilakukan analisis titik impas dalam budidaya kopi arabika Kintamani untuk mengetahui harga yang harus ditetapkan dan tingkat penjualan yang harus dicapai agar petani sebagai produsen tidak mengalami kerugian.

\section{DAFTAR PUSTAKA}

Ayelign, A. K. Sabally. 2013. Determination of Chlorogenic Acids ( CGA) in Coffee Beans Using HPLC. American Journal of Research
Communication. 1(2): 78-91.

Astuti, Retno. 2012. Pengembangan Rantai Pasok Buah Manggis di Kabupaten Bogor, Jawa Barat. Disertasi. Institut Pertanian Bogor

Marimin dan Maghfiroh, N. 2011. Aplikasi Teknik Pengambilan Keputusan dalam Manajemen Rantai Pasok. IPB Press. Bogor.

Mulyadi. 2005, Akuntansi Biaya, Aditya Media, Edisi ke-5, Yogyakarta.

Mulyadi. 2005. Penggolongan biaya. Salemba. Jakarta.

Ponte, Stefano. 2002. The 'Latte Revolution'? Rekopition, Markets and Consumtion in the Global Coffee Chain. World Development, 30(7):1099-1122

Sadayy. 2014. Pengaruh Biaya Produksi Terhadap Laba Perusahaan. Universitas Wiraraja. Madura.

Sucipta, 2016 Pengembangan Sistem Manajemen Rantai Pasok Jeruk Siam yang Berdaya Saing.

Syarif, H., Marimin, Ani, S., Sukardi, Mohamad, Y. 2012. Modifikasi Metode Hayami untuk Perhitungan Nilai tambah pada Rantai Pasok Agroindustri Kelapa Sawit. Jurnal Teknologi Industri Pertanian, 22(1): 22-31. 